\title{
Muscle Strength Variations of Knee Joint Muscles in Elite Female Handball Players after Pre-Season Conditioning
}

\author{
by \\ Zuzana Gonosova ${ }^{1}$, Petr Stastny ${ }^{2}$, Jan Belka ${ }^{1}$, Lucia Bizovska ${ }^{1}$, Michal Lehnert ${ }^{1}$
}

\begin{abstract}
Monitoring seasonal variations in strength performance and the relative risk of injury indicators related to strength of hamstring $(H)$ and quadriceps $(Q)$ in female elite athletes is beneficial for the training process. The aim of this study was to examine and compare the level of muscle strength, the conventional ratio (HCONC/QCONC) as well as two functional and strength ratios reflecting the movement of knee extension (HECC/QCONC) and flexion (HCONC/QECC), and the bilateral percentage strength deficit (BSD) in elite female handball players. The concentric and eccentric isokinetic peak torque was measured at an angular velocity of $60 \%$ on three occasions (in-season cessation, 4 weeks of rest followed by 4 weeks of individual conditioning and 6 weeks of group conditioning) in eleven female handball players (age: $23.1 \pm 3.5$ years, body height: $1.73 \pm 0.6 \mathrm{~m}$ ). According to ANOVA results, the BSD of $H$ muscles in the concentric mode decreased between the in-season cessation and the end of the pre-season, and HCONC/QCONC increased at the beginning of the pre-season and at the end of the pre-season in comparison with inseason cessation measurement. The effect size analyses showed that the off-season rest followed by 10 weeks of the conditioning programme increased $Q$ and $H$ strength in comparison with the previous season with a large effect. Coaches should include progressive conditioning in the pre-season phase to decrease the bilateral strength deficit and to support further conditioning development.
\end{abstract}

Key words: $H / Q$ ratios, bilateral strength deficit, torque, annual training cycle.

\section{Introduction}

Team handball belongs to high-speed sports in which muscle strength is an important variable of handball-specific physical fitness (McHugh, 2004). Strength of the lower extremities is an important predisposition for individual and team execution of various handball skills and actions during a game (McHugh, 2004). Moreover, strength of the knee flexors and extensors and their ratios have also been considered important in prevention of stress factors and risk of injury of the knee and hamstrings (Hughes and Watkins, 2006). The highest incidence of non-contact hamstring and anterior cruciate ligament (ACL) injuries was observed at the age between 15 and 25 years (Bahr and Krosshaug, 2005). A higher prevalence (by $5 \%$ ) of ACL injuries was found in females than in males (Myklebust et al., 2003). Despite the low predictability of ACL injury by muscle strength itself (Steffen et al., 2016), muscle strength changes during the season play an important role in the ACL injury factorial model (Bahr and Krosshaug, 2005; De Ste Croix, 2012; Hughes and Watkins, 2006). Insufficient muscle strength of the hamstring $(\mathrm{H})$ and quadriceps $(\mathrm{Q})$ muscles (Jönhagen et al., 1994), bilateral strength deficits, insufficient ipsilateral concentric $\mathrm{H}$ to $\mathrm{Q}$ ratio (HCONC/QCONC) and eccentric $\mathrm{H}$ to concentric $\mathrm{Q}$ ratio (HECC/QCONC) during the knee extension movement (Dauty et al., 2003) have been reported as relative $\mathrm{H}$ and ACL injury related factors. However, ACL injuries mostly occur in two particular types of movement: singleleg landing, especially after a jump shot and a

1 - Faculty of Physical Culture, Palacky University Olomouc, Czech Republic.

2 - Faculty of Physical Education and Sport, Charles University, Czech Republic. 
rapid change of direction initiated on one leg (De Ste Croix, 2012). In these situations, Q muscles actually work eccentrically and $\mathrm{H}$ muscles must stabilize the knee joint dynamically during the knee flexion movement (HCONC/QECC). For this reason it was proposed to introduce another functional concentric $\mathrm{H}$ to eccentric $\mathrm{Q}$ ratio (HCONC/QECC) to evaluate knee joint function (Aagaard et al., 1998). Nevertheless, use of the HCONC/QECC in elite athletes has been rare so far.

It has been reported that muscle strength and power of the lower extremities alter during the annual training cycle in team sports with regard to a particular training phase and intended neuromuscular adaptations (Lehnert et al., 2014b). The training programmes throughout the annual training cycle may result in muscle imbalances caused by inappropriate adaptation leading to a higher risk of injury of the knee joint (Mujika and Padilla, 2000; Ratamess, 2008). Therefore, decrease in training volume followed by progressive conditioning might be beneficial for eliciting the desired muscle strength development (Siff, 2003).

Taking into account the above mentioned knowledge, monitoring muscle strength of the lower extremities seems to be beneficial especially for training adjustments with respect to recognized muscle deficiencies (McHugh, 2004) and risk of injury (Dauty et al., 2003). However, there are only few studies focusing on changes of muscle strength in male players throughout the different phases of the annual training cycle in team sports (Lehnert et al., 2014a, b). Yet there is a great number of studies focused on the evaluation of isokinetic strength of the lower extremities in female team sports, such as soccer (Brophy et al., 2010), basketball (Cook et al., 2004) and teamhandball (Andrade et al., 2012; Lund-Hanssen et al., 1996; Xaverova et al., 2015). The mentioned studies, however, were of a cross sectional design regardless of the different phases of the annual training cycle, mostly without taking into account the importance of eccentric strength and ipsilateral ratios. To our knowledge, there is a lack of studies determining the effects of off-season and pre-season conditioning on the fitness level in handball players.

Only a limited number of studies focused on thigh muscle strength in female handball players and the effect of off-season and pre-season training exists. Based on muscle strength measurements, peak torque during maximal isokinetic contraction has been considered a representative indicator of muscle strength of the hamstring and quadriceps muscles (Kannus, 1994). Therefore, the aim of the present study was to examine and compare the level of muscle strength, the conventional and two functional $\mathrm{H} / \mathrm{Q}$ strength ratios, and the bilateral percentage strength deficit (BSD) in elite female handball players during and after off-season and preseason conditioning.

\section{Methods}

Participants

The study group consisted of 11 elite female handball players (age: $23.1 \pm 3.5$ years, body height: $1.73 \pm 0.06 \mathrm{~m}$, body mass measurement 1: $76.1 \pm 13.2 \mathrm{~kg}$, body mass measurement 2: $75.4 \pm 13.5 \mathrm{~kg}$, body mass measurement 3: $76.2 \pm 11.7 \mathrm{~kg}$, training experience: $14.3 \pm 4.6$ years) competing in the International Czech-Slovak Inter League. All participants had previous experience with isokinetic testing. The exclusion criteria were selfreported health problems concerning pain during the testing procedure and previous knee injury. The players stated their preferred leg for kicking a ball as their dominant leg (DL), and at the same time stated their contralateral leg that was the take-off leg for a jump shot as non-dominant (NL). The day before testing, the participants were not exposed to intensive training. The participants provided written informed consent. The study was approved by the ethics committee of the Faculty of Physical Culture, Palacky University in Olomouc in accordance with the ethical standards of the Declaration of Helsinki (1983).

\section{Procedures}

Three repeated measurements of isokinetic strength were performed at the following seasonal periods: the first measurement was completed one week after the in-season cessation, the second measurement after the offseason comprising 4 weeks of rest with subsequent 4 weeks of individual conditioning, and the third measurement after another 6 weeks of conditioning at the end of the pre-season (Figure 1).

Bilateral isokinetic strength of knee 
flexors and extensors was assessed using the IsoMed 2000 isokinetic dynamometer (D. \& R. Ferstl GmbH, Hemau, Germany) in a seated position as described earlier by Xaverova et al. (2015). The reliability of measurement had been confirmed by Dirnberger et al. (2012). A nonspecific warm-up was performed on a stationary Kettler ergometer (Heinz Kettler $\mathrm{GmbH}$ and Co. KG, Ense-Parsit, Germany) for 6 minutes at a submaximal intensity of $1.5 \mathrm{~W} / \mathrm{kgBW}$ and a pedal rate of $70-80 \mathrm{rpm}$, and was followed by 10 minutes of dynamic stretching that targeted the main muscle groups involved in testing, and 8 full squats. The warm-up routine was completed under the researcher's supervision.

Testing of the knee extensors and flexors was carried out at an angular velocity of $60 \% \mathrm{~s}$ in the mode of concentric/concentric and eccentric/eccentric reciprocal actions. Between the modes there was a rest period of $2 \mathrm{~min}$, and the rest time between the measurements of the lower limbs was 3 minutes. The starting leg was specified randomly to minimize the effects of learning bias. Prior to each test, the participants performed 4-5 submaximal practice trials as a specific warm-up to become familiar with the test. Thereafter, the participants were instructed to extend/flex the knee as hard and fast as possible throughout the entire range of motion in each of the subsequent testing repetitions. The actual testing in each mode consisted of a set of 4 reciprocal repetitions. The players were notified by a verbal countdown as well as provided with verbal encouragement and visual online feedback to ensure maximum effort. The monitored variable included the normalized peak torque (PT) per body weight. The highest PT was used to determine the conventional ratio Hconc/Qconc, as well as the functional ratios Hecc/Qconc and Hconc/Qecc. Moreover, BSD was determined using the formula (stronger leg - weaker leg)/stronger leg ${ }^{*} 100$, which had been previously reported (Newton et al., 2006).

Training program

The players had a 4-week rest after the inseason cessation; this period was dedicated to mental and physical rest, with non-specific physical activity of moderate intensity. Thereafter, the training program consisted of individual and group conditioning in the pre-season phase as presented in Table 1. Players completed an individual training program for 4 weeks followed by final 6 weeks of group pre-season conditioning. Group training included one or two training sessions daily. The training program was recorded by the head coach.

Statistical Analysis

The resulting variables did not show a normal distribution according to the Shapiro-Wilk test; therefore, non-parametric tests were implemented for further analysis. The Friedman's analysis of variance (ANOVA) and Kendall's coefficient of concordance were computed for the assessment of the main effect. A post-hoc analysis was performed by means of the Wilcoxon signedrank test, and effect size was estimated using the Wilcoxon's Z score by $r=\mathrm{Z} / \sqrt{\mathrm{N}}$, where $\mathrm{N}$ was the number of samples $(\mathrm{N}=11)$. According to Cohen's guidelines, the effect for $r$ was established as follows: large effect $\geq 0.5$, moderate effect $<0.5$ and $\geq 0.3$, and small effect $<0.3$ and $\geq$ 0.1 (Fritz et al., 2012; Maszczyk et al., 2014, 2016). All statistical analyses were performed using the Statistica programme (v. 12, StatSoft, Inc., Tulsa, OK, USA) and Microsoft Excel 2010 (Microsoft Corp., Redmond, Washington, USA). The level of significance was originally set at $\alpha=0.05$, a Bonferroni correction for multiple comparisons (3 comparisons) was applied resulting in the final significance level of $\alpha=0.017$.

\section{Results}

The ANOVA results showed differences in the HCONC/QCONC in the DL $(p<0.01)$ and in the concentric $\mathrm{H}$ bilateral strength deficit $(p=0.02)$ (Table 3). The Hconc/Qconc in the DL was greater after individual and group conditioning in comparison with the in-season cessation testing with a large effect size. The concentric $\mathrm{H}$ bilateral strength deficit decreased after the rest period followed by individual and group conditioning in comparison with the in-season cessation testing with a large effect size.

Despite the significance of the " $p$ " value, the effect size showed that the off-season rest followed by individual conditioning did not result in decreased $\mathrm{H}$ strength (Table 2), with the exception of lower eccentric $\mathrm{H}$ strength of the NL (Table 2) with a large effect. The concentric $Q$ strength in the DL decreased after the period of rest followed by individual conditioning with a large effect. The Hconc in the DL, as well as QeCC 
in the DL and NL were greater after group conditioning than after the in-season cessation with a large effect. The Hconc in the DL, HeCC in the DL, HECC in the NL, QCONC in the DL, QCONC in the NL and Qвсс in the NL were greater after group conditioning compared to after the offseason rest followed by individual training with a large effect.
Except for a significant decrease in HConc/Qconc in the DL, other ipsilateral ratios did not show a large effect between the measurements (Table 3). Besides significance in the concentric $\mathrm{H}$ bilateral strength deficit, the bilateral strength deficit decreased after individual and group conditioning in comparison with the in-season cessation with a large effect.

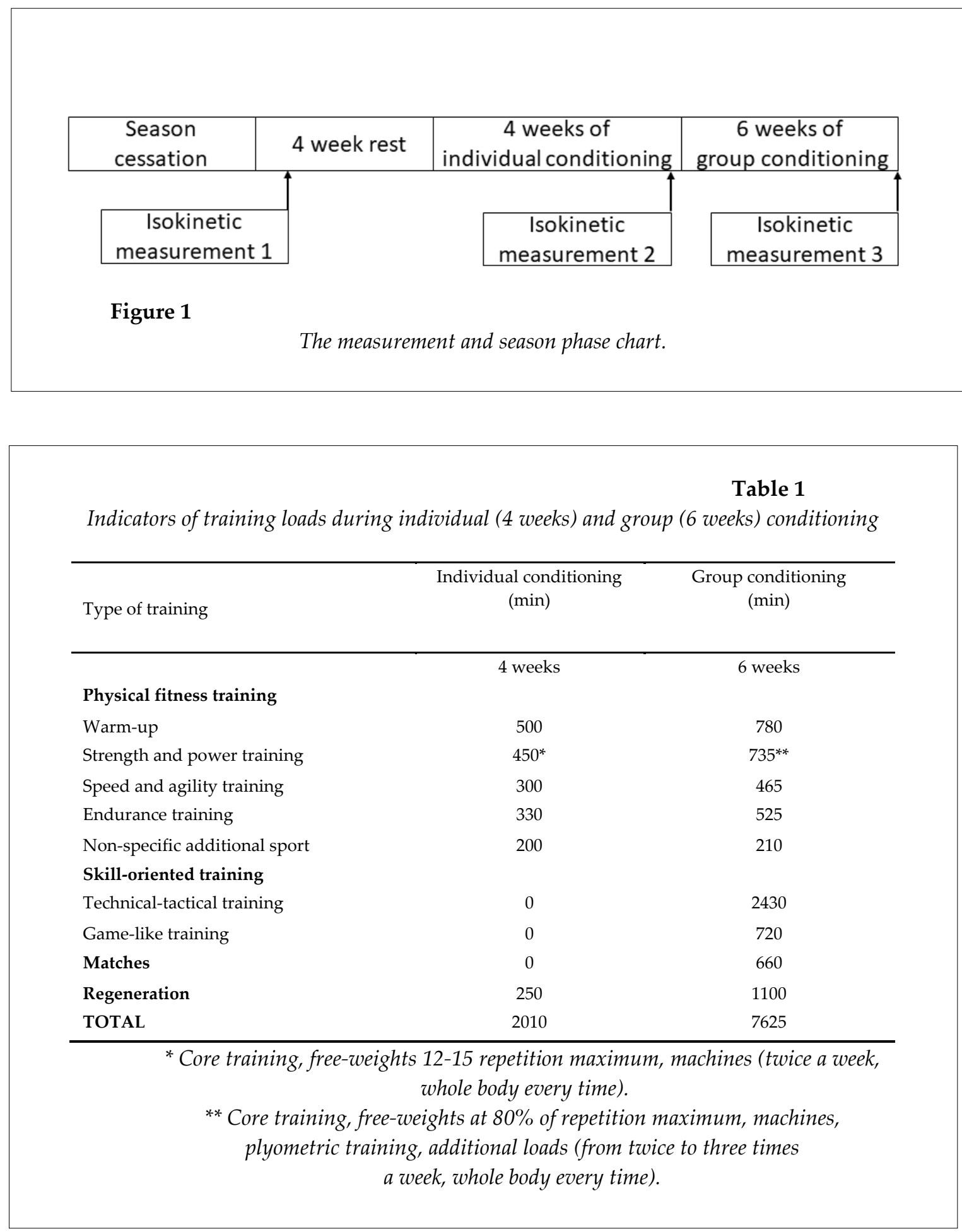


Table 2

Descriptive statistics and Friedman's ANOVA for peak torque of hamstring and quadriceps muscle. Mean $\pm \mathrm{SD}(95 \% \mathrm{CI}) \quad$ Friedman's ANOVA Effect size r

\begin{tabular}{|c|c|c|c|c|c|c|c|c|c|}
\hline Variable & Session 1 & Session 2 & Session 3 & $X^{2}$ & $p$ & W & $S_{1}-S_{2}$ & $S_{1}-S_{3}$ & $S_{2}-S_{3}$ \\
\hline HConc DL & $\begin{array}{l}1.20 \pm 0.22 \\
(1.05-1.35)\end{array}$ & $\begin{array}{l}1.21 \pm 0.22 \\
(1.07-1.36)\end{array}$ & $\begin{array}{l}1.29 \pm 0.20 \\
(1.16-1.42)\end{array}$ & 5.09 & 0.078 & 0.23 & 0.03 & 0.67 & 0.54 \\
\hline Hecc DL & $\begin{array}{l}1.45 \pm 0.32 \\
(1.24-1.66)\end{array}$ & $\begin{array}{l}1.44 \pm 0.29 \\
(1.24-1.63)\end{array}$ & $\begin{array}{l}1.53 \pm 0.26 \\
(1.35-1.70)\end{array}$ & 5.09 & 0.078 & 0.23 & 0.05 & 0.43 & 0.54 \\
\hline Hconc NL & $\begin{array}{l}1.22 \pm 0.25 \\
(1.05-1.39)\end{array}$ & $\begin{array}{l}1.20 \pm 0.24 \\
(1.04-1.36)\end{array}$ & $\begin{array}{l}1.25 \pm 0.21 \\
(1.11-1.39)\end{array}$ & 2.36 & 0.307 & 0.11 & 0.27 & 0.19 & 0.29 \\
\hline Hecc NL & $\begin{array}{l}1.46 \pm 0.32 \\
(1.25-1.68)\end{array}$ & $\begin{array}{l}1.35 \pm 0.33 \\
(1.13-1.57)\end{array}$ & $\begin{array}{l}1.49 \pm 0.21 \\
(1.35-1.63)\end{array}$ & 3.82 & 0.148 & 0.17 & 0.48 & 0.21 & 0.56 \\
\hline Qconc DL & $\begin{array}{l}2.27 \pm 0.36 \\
(2.03-2.51)\end{array}$ & $\begin{array}{l}2.14 \pm 0.36 \\
(1.90-2.38)\end{array}$ & $\begin{array}{l}2.31 \pm 0.31 \\
(2.10-2.51)\end{array}$ & 5.09 & 0.078 & 0.23 & 0.51 & 0.05 & 0.62 \\
\hline Q всс DL & $\begin{array}{l}2.53 \pm 0.67 \\
(2.08-2.98)\end{array}$ & $\begin{array}{l}2.70 \pm 0.63 \\
(2.27-3.12)\end{array}$ & $\begin{array}{l}2.89 \pm 0.67 \\
(2.44-3.34)\end{array}$ & 1.27 & 0.529 & 0.06 & 0.27 & 0.54 & 0.43 \\
\hline Qconc NL & $\begin{array}{l}2.19 \pm 0.32 \\
(1.98-2.40)\end{array}$ & $\begin{array}{l}2.14 \pm 0.37 \\
(1.89-2.39)\end{array}$ & $\begin{array}{l}2.32 \pm 0.31 \\
(2.11-2.52)\end{array}$ & 4.55 & 0.103 & 0.21 & 0.32 & 0.48 & 0.54 \\
\hline$Q_{\text {всс }} \mathrm{NL}$ & $\begin{array}{l}2.59 \pm 0.69 \\
(2.13-3.06)\end{array}$ & $\begin{array}{l}2.65 \pm 0.84 \\
(2.08-3.21)\end{array}$ & $\begin{array}{l}3.00 \pm 0.53 \\
(2.64-3.35)\end{array}$ & 2.91 & 0.234 & 0.13 & 0.11 & 0.62 & 0.59 \\
\hline
\end{tabular}

$H$ - hamstring muscles, $Q$ - quadriceps muscles, CONC - concentric mode, ECC - eccentric mode, $D L$ - dominant leg, $N L$ - non-dominant leg,

Session 1 -after in-season cessation, Session 2 -beginning of the pre-season, Session 3 -end of the pre-season, SD - standard deviation, CI - confidence interval, $X^{2}$ - chi-squared, $W$ - Kendall coefficient of concordance, Effect size $r: r \geq 0.5$ is large effect, $r<0.5$ and $\geq 0.3$ is moderate effect, $r<0.3$ and $\geq 0.1$ is small effect. 
Table 3

Descriptive statistics and Friedman's ANOVA for ipsilateral ratios and bilateral strength deficits Mean \pm SD $(95 \% \mathrm{CI}) \quad$ Friedman's ANOVA Effect size $\mathrm{r}$

$\begin{array}{llllllllll}\text { Variable } & \text { Session } 1 & \text { Session } 2 & \text { Session } 3 & X^{2} & p & W & S_{1}-S_{2} & S_{1}-S_{3} & S_{2}-S_{3}\end{array}$

\begin{tabular}{|c|c|c|c|c|c|c|c|c|c|}
\hline \multicolumn{10}{|l|}{ Ipsilateral H/Q ratios } \\
\hline HCONC/QCONC DL & $\begin{array}{l}0.53 \pm 0.04 \\
(0.50-0.55)\end{array}$ & $\begin{array}{l}0.57 \pm 0.06 \\
(0.53-0.61)\end{array}$ & $\begin{array}{l}0.56 \pm 0.04 \\
(0.53-0.59)\end{array}$ & 10.36 & $0.006^{*}$ & 0.47 & 0.72 & 0.67 & 0.46 \\
\hline HCONC/QCONC NL & $\begin{array}{l}0.56 \pm 0.11 \\
(0.49-0.63)\end{array}$ & $\begin{array}{l}0.57 \pm 0.10 \\
(0.50-0.63)\end{array}$ & $\begin{array}{l}0.54 \pm 0.07 \\
(0.49-0.59)\end{array}$ & 1.27 & 0.529 & 0.06 & 0.11 & 0.27 & 0.35 \\
\hline Hecc/Qconc DL & $\begin{array}{l}0.64 \pm 0.13 \\
(0.56-0.73)\end{array}$ & $\begin{array}{l}0.68 \pm 0.11 \\
(0.60-0.75)\end{array}$ & $\begin{array}{l}0.66 \pm 0.09 \\
(0.61-0.72)\end{array}$ & 1.64 & 0.441 & 0.07 & 0.38 & 0.35 & 0.05 \\
\hline HeCc/Qconc NL & $\begin{array}{l}0.67 \pm 0.12 \\
(0.59-0.75)\end{array}$ & $\begin{array}{l}0.63 \pm 0.12 \\
(0.55-0.72)\end{array}$ & $\begin{array}{l}0.65 \pm 0.09 \\
(0.59-0.71)\end{array}$ & 2.36 & 0.307 & 0.11 & 0.40 & 0.32 & 0.11 \\
\hline Hconc/Qecc DL & $\begin{array}{l}0.49 \pm 0.12 \\
(0.41-0.57)\end{array}$ & $\begin{array}{l}0.46 \pm 0.05 \\
(0.42-0.49)\end{array}$ & $\begin{array}{l}0.46 \pm 0.07 \\
(0.41-0.51)\end{array}$ & 2.36 & 0.307 & 0.11 & 0.35 & 0.32 & 0.05 \\
\hline HConc/QeccNL & $\begin{array}{l}0.49 \pm 0.14 \\
(0.40-0.59)\end{array}$ & $\begin{array}{l}0.48 \pm 0.14 \\
(0.39-0.58)\end{array}$ & $\begin{array}{l}0.42 \pm 0.07 \\
(0.38-0.47)\end{array}$ & 1.27 & 0.529 & 0.06 & 0.19 & 0.40 & 0.51 \\
\hline \multicolumn{10}{|l|}{ Bilateral strength deficit } \\
\hline HCONC & $\begin{array}{l}13.6 \pm 9.3 \\
(7.4-19.9)\end{array}$ & $\begin{array}{c}8.9 \pm 5.5 \\
(5.2-12.6)\end{array}$ & $\begin{array}{l}6.7 \pm 4.1 \\
(3.9-9.5)\end{array}$ & 7.82 & $0.020^{*}$ & 0.04 & 0.46 & 0.78 & 0.56 \\
\hline Hecc & $\begin{array}{c}9.1 \pm 5.0 \\
(5.8-12.5)\end{array}$ & $\begin{array}{l}10.2 \pm 9.0 \\
(4.2-16.3)\end{array}$ & $\begin{array}{l}11.6 \pm 9.5 \\
(5.2-18.0)\end{array}$ & 0.18 & 0.913 & 0.01 & 0.03 & 0.11 & 0.00 \\
\hline QCONC & $\begin{array}{c}9.5 \pm 6.8 \\
(4.9-14.0)\end{array}$ & $\begin{array}{l}4.9 \pm 5.8 \\
(1.0-8.8)\end{array}$ & $\begin{array}{l}6.2 \pm 3.5 \\
(3.9-8.6)\end{array}$ & 4.55 & 0.103 & 0.21 & 0.67 & 0.54 & 0.32 \\
\hline QécC & $\begin{array}{l}15.3 \pm 9.2 \\
(9.2-21.5)\end{array}$ & $\begin{array}{l}11.9 \pm 9.3 \\
(5.7-18.2)\end{array}$ & $\begin{array}{l}10.0 \pm 9.4 \\
(3.7-16.3)\end{array}$ & 1.27 & 0.529 & 0.06 & 0.16 & 0.40 & 0.32 \\
\hline
\end{tabular}

$H$ - hamstring muscles, $Q$ - quadriceps muscles, CONC - concentric mode, ECC-eccentric mode, DL - dominant leg, NL - non-dominant leg,

Session 1 -after in-season cessation, Session 2 -beginning of the pre-season, Session 3 -end of the pre-season, SD - standard deviation, CI - confidence interval, $X^{2}$ - chi-squared, $W$-Kendall coefficient of concordance, Effect size $r: r \geq 0.5$ is large effect, $r<0.5$ and $\geq 0.3$ is moderate effect, $r<0.3$ and $\geq 0.1$ is small effect, ${ }^{*}$ significant difference. 


\section{Discussion}

The main finding of the present study is that muscle strength did not significantly decrease after 4 weeks of rest followed by 4 weeks of individual training, and that muscle strength increased after a 6-week group conditioning in comparison with the strength level in the previous season. This finding is in agreement with the recommendation to use a rest period followed by a progressive conditioning block (Siff, 2003). Furthermore, muscle imbalances represented by BSD of $\mathrm{H}$ muscles and Hconc/Qconc were reduced at the end of the pre-season in comparison with in-season cessation measurement, which is one of the desired goals of this part of the annual training cycle. Although the presented conditioning programme did not include specific exercises for muscle imbalance reduction, the offseason rest followed by individual conditioning had a positive effect on muscle strength and muscle imbalances in the following conditioning programme.

Muscle strength level of hamstring and quadriceps

The effect size analyses showed an increase in $\mathrm{H}$ and $\mathrm{Q}$ strength during pre-season conditioning in concentric and eccentric strength of $\mathrm{H}$ muscles and concentric strength of $\mathrm{Q}$ muscles in both lower limbs with large effect sizes $(r>0.5)$. On the other hand, there was a nonsignificant progressive increasing trend in $Q$ eccentric strength over the observed periods with medium-to-large effect sizes in both lower limbs $(r=0.43-0.59)$. In fact, general muscle strength development reflected in the measurement results should be implemented during the off-season, and maximal strength development followed by its conversion to handball-specific and explosive strength should be planned in the pre-season (Ratamess, 2008), which was included in the group conditioning phase of the program described in this paper.

With regard to the annual training cycle, a previously reported study (Xaverova et al., 2015) focusing on concentric PT in $\mathrm{H}$ and $\mathrm{Q}$ muscles at an angular velocity of $60 \%$ presented the results of female handball players with national (DL and $\mathrm{NL}: \mathrm{H}=1.2$ and $\mathrm{Q}=2.2 \mathrm{Nm} / \mathrm{kg}$ ) and junior national team experience (DL: $\mathrm{H}=1.4$ and $\mathrm{Q}=2.3$ $\mathrm{Nm} / \mathrm{kg}$; $\mathrm{NL}: \mathrm{H}=1.3$ and $\mathrm{Q}=2.4 \mathrm{Nm} / \mathrm{kg}$ ). The stated values were similar to the corresponding findings of the present study. Comparable results concerning identical periods can also be observed in female volleyball players as an average of DL and $\mathrm{NL}(\mathrm{H}=1.21$ and $\mathrm{Q}=2.38 \mathrm{Nm} / \mathrm{kg}$ ) (Fry et al., 1991), however, it has been reported that specific demands in various sports produce differences in muscle strength ratios (Ratamess, 2008).

Since landing impact forces with immediate subsequent rapid actions, especially insufficient strength of $\mathrm{H}$ muscles are associated with ACL injury among female handball players, thus eccentric isokinetic torque evaluation of the knee muscles seems to be crucial. Regarding the fact that the normalized eccentric PT values in $\mathrm{H}$ and $Q$ muscles in a similar senior (DL: $H=1.4$ and $\mathrm{Q}=2.8 \mathrm{Nm} / \mathrm{kg} ; \mathrm{NL}: \mathrm{H}=1.4$ and $\mathrm{Q}=2.9 \mathrm{Nm} / \mathrm{kg}$ ) and a similar junior population (DL: $\mathrm{H}=1.5$ and $\mathrm{Q}=3.0 \mathrm{Nm} / \mathrm{kg} ; \mathrm{NL}: \mathrm{H}=1.4$ and $\mathrm{Q}=2.9 \mathrm{Nm} / \mathrm{kg}$ ) were comparable at the beginning of the preseason (Xaverova et al., 2015), the values observed in this study were not reported as insufficiently low. Although the results may be compared with previous studies on female athletes (Andrade et al., 2012; Brophy et al., 2010; Cook et al., 2004; Lund-Hanssen et al., 1996), the comparison of eccentric strength is possible only with one reference value (Xaverova et al., 2015).

Bilateral strength deficit

Bilateral strength asymmetries may possibly affect player's performance either by increasing the risk of injury or by limiting the player, thus favouring their stronger side. Correction of such an imbalance may improve performance and also reduce the risk of injury (Newton et al., 2006). In the present study, a significant decrease in asymmetry with a large effect was found in BSD in $\mathrm{H}$ muscles in the concentric mode between the in-season cessation and the end of pre-season conditioning (from 13.6 to $6.7 \%, p=0.009, r=0.78)$. Generally, a bilateral difference of $10-15 \%$ between muscle groups may be considered significant and could be a criterion to hold an athlete out of practice or competition until the strength asymmetry is corrected (Maly et al., 2015), therefore conditioning after rest in our study had a positive effect on muscle imbalances. A trend of higher BSD in $\mathrm{H}$ and $\mathrm{Q}$ muscles (> $10 \%$ ) was observed in the eccentric mode of testing in comparison with the concentric mode of testing in three individual measurements. In any case, by placing too much emphasis on the stronger leg, players may increase the potential 
for injury when considering eccentric strength (Lockie et al., 2012).

There are two different approaches to bilateral strength comparisons in term of PT preference of the dominant leg and preference of the stronger leg (\% Def) (Beam and Gene, 2014). Regarding the fact that a higher incidence of ACL injuries (by $68 \%$ ) on their NLs (DL $=$ preference to kick a ball) was observed in female soccer players (Brophy et al., 2010), this approach was used for the purposes of the present study. Moreover, a clear trend of the stronger leg in both testing modes throughout all testing sessions in the concentric and eccentric mode was not observed. Specifically, when referring to the jump shot handball skill, neither the stronger take-off leg nor non-take-off leg dominance is observed. Furthermore, the weaker leg is limited in horizontal ground reaction force production during the stance phase of running in comparison with the stronger leg, which leads to a potential reduction in step length and an inefficient step pattern (Brughelli et al., 2010).

Ipsilateral hamstring to quadriceps ratio

Hamstrings and quadriceps muscles serve as important dynamic stabilizers of the knee joint. Unless agonist-antagonist muscle groups are in a certain balance, the weaker muscle group as well as the corresponding joint are usually more predisposed to injury. The value of $100 \%$ (or 1.0 ratio) indicates a balance between peak torque of knee flexors and extensors and therefore, the optimal ability of dynamic stabilization of the knee joint (Coombs and Garbutt, 2002).

Although a significant increase with large effects of time in the average Hconc/Qconc in the DL between the in-season cessation and rest followed by individual conditioning block (from 0.53 to $0.57, p=0.016, r=0.72$ ) and between the inseason cessation and the end of the pre-season (from 0.53 to $0.56, p=0.026, r=0.67$ ) was detected, its level was low compared with the critical value (0.6). This is also true for eccentric muscle strength insufficiency of the hamstring muscles over the whole observed period when referring to the border value of the Hecc/Qconc ratio (0.7) (Coombs and Garbutt, 2002) as the players' Hecc/Qconc ratios varied between the values of $0.63-0.68$. On the other hand, the conditioning program did not include the generally recommended hamstring eccentric exercises (Al Attar et al., 2017; Mjølsnes et al., 2004). Therefore, it may be concluded that the off-season rest, followed by non-specific 4 weeks of individual conditioning is not sufficient to improve Hecc/Qconc, but may improve the Hconc/Qconc in the DL. Combining the in-season rest period with specific exercises aimed at the lower extremities may effectively reduce the risk factors for ACL injuries.

No repeated measures studies concerning changes in conventional and/or functional H/Q ratios during the annual training cycle in female athletes have been found; therefore, the results of the present study are hard to compare. Nevertheless, the current knowledge about female handball players reporting HConc/Qconc at the level of 0.56 (Andrade et al., 2012; Lund-Hanssen et al., 1996) and 0.56-0.58 (Xaverova et al., 2015) indicates that handball may be considered a sport discipline with overloaded $Q$ muscles that can negatively affect knee joint dynamic stability. To the best of our knowledge, there is only one study reporting the Hecc/Qconc in female handball players with a ratio of $0.66(\mathrm{DL})$ and $0.67(\mathrm{NL})$ in players with experience in the woman's national team, and a ratio of 0.66 (DL) and 0.62 (NL) in players with experience in the junior national team at the beginning of the pre-season (Xaverova et al., 2015).

The ipsilateral ratios Hconc/Qconc and Hecc/Qconc relate to knee extension; however, injuries in handball mostly occur in two specific types of movement: single-leg landing, especially after a jump shot and rapid change of direction initiated on one leg, that is during knee flexion which can be described by the Hconc/Qecc (De Ste Croix, 2012). These injuries occur as a result of large external valgus moment and external rotation moment in combination with a translatory shift of the tibia relative to the femur usually in large knee angles close to full extension (Bahr and Krosshaug, 2005). These injuries usually happen during defensive play, and are more frequent in high-level competition or after years of training (Myklebust et al., 2003). Knowing this, it is quite surprising that the use of Hconc/Qеcc in athletes is infrequent. Aagaard et al. (1998) reported a Hconc/QесC around 0.30 at a velocity of $240 \%$ in male and female track and field athletes suggesting that the $\mathrm{H}$ muscles had a reduced capacity for dynamic knee joint stabilization during forceful knee flexion 
movements with simultaneous eccentric quadriceps muscle contraction. The Hconc/Qecc decreases with increases in flexion velocity that is contrary to the functional ratio representative for knee extension (HEcC/QCONC) that increases with increases in extension velocity (Aagaard et al., 1998). The Hconc/Qecc in the present study was more or less stable under the value of 0.5 at a velocity of $60 \%$ s. An insufficient level of $\mathrm{H}$ muscles during this action may alternate the natural landing technique with further mechanisms leading to injury. Moreover, it was also reported that knee valgus alignment typical for females may increase the risk of injury, which is even higher with fatigue accumulated during a game or over a long training session (De Ste Croix, 2012).

Despite this fact, besides the Hconc/Qconc, two other functional ratios (Hecc/Qconc and Hconc/Qecc) that account for the role of the antagonist in knee joint stabilisation have been observed in ACL injury specific knee angles (Aagaard et al., 1998). This may be explored in further studies. Although flexibility of the knee joint muscles influences muscle strength production (Ayala et al., 2012), flexibility was not investigated in the present study. Another limitation of the study refers to a small sample size; therefore, this fact has to be taken into account in data interpretation. However, similar numbers of participants involved in studies on high-performance athletes are common in the literature (Lehnert et al., 2014a, b; Xaverova et al., 2015). Moreover, for practical implications, when considering confidence intervals in the observed variables, it is important to realize that a group average tends to mask norm ranges of individual bilateral and ipsilateral asymmetries.

\section{Conclusions}

The off-season rest period followed by the conditioning block had two main positive effects, a reduction in BSD and an increase in the Hconc/Qconc. However, the requirements for strength improvement in a 10-week conditioning cycle are generally higher than it was observed. Therefore, the presented conditioning program should be improved in the area of specific lower extremity exercises, which may support the positive influence of off-season conditioning.

Coaches should include a training rest period after the competitive period to decrease the bilateral strength deficit and support further fitness development. Furthermore, coaches and conditioning specialists should report representative values of muscle strength levels (e.g. isokinetic peak torque) with a clear record of the phase of the annual training cycle.

\section{Acknowledgements}

This study was a part of a research project of the Faculty of Physical Culture, Palacky University Olomouc, Czech Republic (No. IGA_FTK_2012_006) and Project UNCE/HUM/032 at Charles University in Prague.

\section{References}

Aagaard P, Simonsen EB, Magnusson SP, Larsson B, Dyhre-Poulsen P. A new concept for isokinetic hamstring: quadriceps muscle strength ratio. Am J Sports Med, 1998; 26: 231-237

Al Attar WSA, Soomro N, Sinclair PJ, Pappas E, Sanders RH. Effect of injury prevention programs that include the Nordic hamstring exercise on hamstring injury rates in soccer players: A systematic review and meta-analysis. J Sci Med Sport, 2017; 20: 907-916

Andrade MDS, De Lira CAB, Koffes FDC, Mascarin NC, Benedito-Silva AA, Da Silva AC. Isokinetic hamstrings-to-quadriceps peak torque ratio: The influence of sport modality, gender, and angular velocity. J Sports Sci, 2012; 30: 547-553

Ayala F, Sainz de Baranda P, De Ste Croix M, Santonja F. Absolute reliability of five clinical tests for assessing hamstring flexibility in professional futsal players. J Sci Med Sport, 2012; 15: 142-147

Bahr R, Krosshaug T. Understanding injury mechanisms: A key component of preventing injuries in sport. Br J Sports Med, 2005; 39: 324-329

Beam WC, Gene MA. Isokinetic strength. United States of America, NY: McGraw-Hill Education, 55-72; 2014 
Brophy R, Silvers HJ, Gonzales T, Mandelbaum BR. Gender influences: the role of leg dominance in ACL injury among soccer players. Br J Sports Med, 2010; 44: 694-697

Brughelli M, Cronin J, Mendiquchia J, Kinsella D, Nosaka K. Contralateral leg deficits in kinetic and kinematic variables during running in Australian rules football players with previous hamstring injuries. J Strength Cond Res, 2010; 24: 2539-2544

Cook JL, Gaida JE, Bass SL, Austen S, Kiss ZS. Are unilateral and bilateral patellar tendinopathy distinguished by differences in anthropometry, body composition, or muscle strength in elite female basketball players? Br J Sports Med, 2004; 38: 581-585

Coombs R, Garbutt G. Developments in the use of the hamstring/quadriceps ratio for the assessment of muscle balance. J Sports Sci Med, 2002; 1: 56-62

Dauty M, Potiron-Josse M, Rochcongar P. Identification of previous hamstring muscle injury by isokinetic concentric and eccentric torque measurement in elite soccer player. Isokinet Exerc Sci, 2003; 11: 139144

De Ste Croix M. Protect her knees-Exploring the role of football specific fatigue on dynamic knee stability in female youth football players. University of Gloucestershire: UEFA Research Grant Programme, 1-112; 2012

Dirnberger J, Wiesinger H-P, Kösters A, Müller E. Reproducibility for isometric and isokinetic maximum knee flexion and extension measurements using the IsoMed 2000-dynamometer. Isokinet Exerc Sci, 2012; 20: 149-153

Fritz CO, Morris PE, Richler JJ. Effect size estimates: Current use, calculations, and interpretation. Journal of Experimental Psychology: General, 2012; 141: 2-18

Fry AC, Kraemer WJ, Gordon SE, Weseman CA, Conroy BP, Hoffman JR, Maresh CM. The effects of an offseason strength and conditioning program on starters and non-starters in women's intercollegiate volleyball. J Strength Cond Res, 1991; 5: 174-181

Hughes G, Watkins J. A risk-factor model for anterior cruciate ligament injury. Sports Med, 2006; 36: 411-428

Jönhagen S, Németh G, Eriksson E. Hamstring injuries in sprinters. The role of concentric and eccentric hamstring muscle strength and flexibility. Am J Sports Med, 1994; 22: 262-266

Kannus P. Isokinetic evaluation of muscular performance: implications for muscle testing and rehabilitation. Int J Sports Med, 1994; 15: S11-18

Lehnert M, Psotta R, Chvojka P, Ste Croix MD. Seasonal variation in isokinetic peak torque in youth soccer players. Kinesiology, 2014a; 46: 79-87

Lehnert M, Xaverová Z, De Ste Croix M. Changes in muscle strength in U19 soccer players during an annual training cycle. J Hum Kinet, 2014b; 42: 175-185

Lockie RG, Schultz AB, Jeffriess MD, Callaghan SJ. The relationship between bilateral differences of knee flexor and extensor isokinetic strength and multi-directional speed. Isokinet Exerc Sci, 2012; 20: 211219

Lund-Hanssen H, Holen K, Hammer S, Gannon J, Engebretsen L. Isokinetic muscle performance in healthy female handball players and players with a unilateral anterior cruciate ligament reconstruction. Scand J Med Sci Sports, 1996; 6: 172-175

Maly T, Zahalka F, Mala L, Cech P. The bilateral strength and power asymmetries in untrained boys. Open Med, 2015; 10: 2

Maszczyk A, Gołaś A, Pietraszewski P, Roczniok R, Zając A, Stanula A. Application of Neural and Regression Models in Sports Results Prediction. Procedia - Soci Behavio Sci, 2014; 117: 482-487

Maszczyk A, Golas A, Czuba M, Krol H, Wilk M, Stastny P, Goodwin J, Kostrzewa M, Zajac A. EMG Analysis and Modelling of Flat Bench Press Using Artificial Neural Networks. SAJRPER. 2016; 38(1): 91-103

McHugh MP. The prevention of muscle strains in sport: Effective pre-season interventions? INT SPORTMED J, 2004; 5: 177-187

Mjølsnes R, Arnason A, Østhagen T, Raastad T, Bahr R. A 10-week randomized trial comparing eccentric vs. concentric hamstring strength training in well-trained soccer players. Scand J Med Sci Sports, 2004; 14: 311-317

Mujika I, Padilla S. Detraining: Loss of training-induced physiological and performance adaptations. Part I: 
Short term insufficient training stimulus. Sports Med, 2000; 30: 79-87

Myklebust G, Engebretsen L, Braekken I, Skjolberg A, Olsen O, Bahr R. Prevention of anterior cruciate ligament injuries in female team handball players: a prospective intervention study over three seasons. Scand J Med Sci Sports, 2003; 13: 272-272

Newton RU, Gerber A, Nimphius S, Shim JK, Doan BK, Robertson M, Pearson DR, Craig BW, Häkkinen K, Kraemer WJ. Determination of functional strength imbalance of the lower extremities. J Strength Cond Res, 2006; 20: 971-977

Ratamess NA. Adaptations to anaerobic training programs. Champaign, IL: Human Kinetics, 93-120; 2008

Siff MC. Supertraining. Denver, CO: Supertraining Institute, 83-115; 2003

Steffen K, Nilstad A, Kristianslund EK, Myklebust G, Bahr R, Krosshaug T. Association between lower extremity muscle strength and noncontact ACL injuries. Med Sci Sports Exerc, 2016; 48: 2082-2089

Xaverova Z, Dirnberger J, Lehnert M, Belka J, Wagner H, Orechovska K. Isokinetic strength profile of elite female handball players. J Hum Kinet, 2015; 49: 257-266

\section{Corresponding author:}

\section{Petr Stastny}

Charles University, Faculty of physical education and Sport, Jose Martiho 31, Prague 6, 162 52, Czech Republic;

Phone number +420777198764

E-mail: stastny@ftvs.cuni.cz 